\title{
The Cohesion and Coherence of the Editorials in The Jakarta Post
}

\author{
Prayudha \\ Ahmad Dahlan University Yogyakarta \\ prayudha@pbi.uad.ac.id
}

\begin{abstract}
Concept of discourse involves three dimensions that are as language use, communication of beliefs (human cognition), and interaction in social situation. As a language use, discourse consists of two elements: cohesion and coherence. Discourse is divided into spoken and written discourse. Written discourse such as newspaper is very familiar today. One of the famous newspapers in Indonesia is The Jakarta Post. The most essential article in a newspaper is its editorial. Therefore, the research has been intended to find cohesion and coherence devices of the editorials in The Jakarta Post. In this research, substantive data were texts consisting of cohesion and coherence devices. The sources were editorials in The Jakarta Post May 2011 edition that consisted of 28 editorial articles. The data was analyzed using Identity Method. Results of the analysis showed that editorials in The Jakarta Post May 2011 contain all kinds of cohesion and coherence devices. The editorials contain grammatical cohesion (reference, ellipsis, substitution, conjunction) and lexical cohesion (reiteration and collocation). Coherence devices (repetition, personal reference, transition) are also contained in the data.
\end{abstract}

Key words: discourse, cohesion, coherence, editorial, and The Jakarta Post.

\section{A. Introduction}

Language is a system of arbitrary vocal symbols used for human communication. All of symbolic phenomena which occur in the universe are described by language. By language people get knowledge about the universe. Bussmann (2006: 627) defines that language is a vehicle for the expression or exchanging of thoughts, concepts, knowledge, and information as well as the fixing and transmission of experience and knowledge. Language in communication is meaningful when it is arranged well and relevant with the context surrounding the communication.

The arrangement and the relevance of language used in a communication can be explained as a discourse. The term discourse itself is very ambiguous. At first opinion, discourse focuses on an analysis of verbal structures and cognitive process but another opinion claims that discourse 
focuses on interaction in society. However, discourse in general can be distinguished into three focuses.

...the concept of discourse, we already have encountered its three main dimension: (a) Language use, (b) the communication of beliefs (cognition), and (c) interaction in social situation. Given these three dimensions, such as linguistics (for the specific study of language and language use), psychology (for the study of beliefs and how they are communicated), and the social sciences (for the analysis of interactions in social situations). (Van Dijk, 1997 :3)

In linguistics, Stubbs (1983: 1) states that discourse is a study of the organization of language above sentence or above clause, and therefore to study larger linguistic units, such us conversational exchanges or written texts. It follows that study of discourse is wider than other linguistic studies that only focus in sentence analysis. Discourse analyzes not only describing composition of sentence but also the composition of whole text which contains more than one sentence. In other words, discourse has higher occupation than phoneme, morpheme, word, phrase, clause, and sentence.

There are two terms that are very fundamental in discourse analysis which studies the relation among a text within the other texts that are cohesion and coherence. Cohesion is the use of language forms to indicate semantic relations between elements in a discourse. Bussmann (1998: 199) says that cohesion refers to the various linguistic means (grammatical, lexical, and phonological) by which sentences 'stick together' and are linked into larger units of paragraphs, or stanzas, or chapters. There are two main types of cohesion: grammatical, referring to the structural content, a lexical, referring to the language content of the piece.

Coherence is grammatical and semantic interconnectedness between sentences that form a text. According to Van Dijk (1997: 9) coherence is how the meaning of sentences in a discourse hung together. It is the semantic structure, not its formal meaning, which create coherence. Coherency is a condition where sentences in a text hang together. It can occur in relation of sentences that immediately follow each other. Coherency grammatically arises when a text contains transition signals or when it possesses consistent pronoun. Semantically, a text is said coherence when there is unity of meaning among elements of the texts.

In a discourse analysis, sometimes, it is difficult to describe and differentiate the terms of cohesion and coherence. Mulyana (2005: 36) argues that cohesion and coherence are difficult to be determined and differentiated. However, he also says that a research about discourse analysis especially in relation to cohesion and coherence is much needed. The two elements can be a sophisticated formula in producing good and effective discourse especially in written discourse. 


\section{B. Methodology}

The research observed cohesion and coherence of the editorials in The Jakarta Post May 2011 edition as the object of the research. To identify and analyze the object of a research, the research determined the research types. Sudaryanto (1986: 63) states, "There are two types of research namely quantitative research and qualitative research." Quantitative research is a research includes any type of research based on percentage, average, chi-square and other statistical computations. Qualitative research is a research procedure that results in descriptive data in written and spoken forms in the language community. The research is fully a qualitative research.

The research used Observing Method to gather data from 28 editorials article of The Jakarta Post May edition in researching the pattern and function of cohesion and coherence of the research object. Sudaryanto (1993: 132) states that there are two methods of gathering data in linguistic research, namely Observing Method and Interviewing Method.

According to Haugen (1971 in Sudaryanto, 1993: 15 in Muhammad, 2011: 224) there are three primary methods to analyze the data that are Identity Method, Distributional Method, and Introspective Method. The research used Identity Method. After analyzing the data, the research finding was displayed through Informal Method to display the data.

\section{Discussion}

\section{Cohesion in the Editorials of The Jakarta Post}

Cohesion in discourse means solidity form which structurally establish syntactical tie. Moeliono (1988:34 in Mulyana, 2005: 26) asserts that a good and solid discourse occurs from cohesive sentences. Furthermore, cohesion refers to the various linguistic means (grammatical, lexical, and phonological) by which sentences 'stick together' and are linked into larger units of paragraphs, or stanzas, or chapters. Cohesive relation is signed by using cohesive device. According to Halliday and Hasan (1976: 6) there are two cohesion devices namely grammatical cohesion and lexical cohesion. Grammatical cohesion is realized through the grammar and lexical one is realized through vocabulary.

\section{a. Grammatical Cohesion}

According to Halliday and Hasan (1976: 4), cohesion occurs when the interpretation of some elements in the discourse is dependent on that of another. It concludes that the one element presupposes the other. The element cannot be effectively decoded except by recourse to it. Moreover, the basic concept of it is a semantic one. It refers to relations of meaning that exists within the text. So, when this happens, a relation of cohesion is set up, and the two elements, the presupposing and the presupposed, are thereby integrated into a text. Halliday and Hasan (1976: 39) classify grammatical cohesion into reference, substitution, ellipsis and conjunction. 


\section{1) Reference}

Reference is the specific nature of the information that is signaled for retrieval. Based on the place of reference, the interpretation of reference can be divided into endophora (textual) and exophoric (situational) reference (Halliday and Hasan, 1976: 33). When the interpretation of a reference lies within the boundaries of text, it is called endophoric relation. This relation forms cohesive ties within the text. There are two kinds of endophoric relations: anaphora and cataphora. Anaphora is the presupposition of something that has gone before, whether in the preceding sentence or not. It is a form of presupposition that refers to some previous item. In contrary, cataphora refers to the presupposition in the opposite direction, with the presupposed element following (Halliday and Hasan, 1976: 17). Both anaphoric and cataphoric references use personal reference or pronominal reference, demonstrative reference and comparative reference (Halliday and Hasan, 1976: 37).

Personal reference is reference by means of function in the speech situation, through the category of person (Halliday and Hasan, 1976: 37). The personal references found in the editorials of The Jakarta Post May 2011 edition consist of personal pronoun and possessive determiners. Several personal pronouns above are endophoric and include anaphoric references except the personal pronoun it that is a cataphoric reference. There is also an exophoric personal pronoun that is we. Almost all of the possessive determiners above are endhoporic and anaphoric excepts our which is exophoric. The personal pronouns in the editorials prove that it presuppose the person or object in the speech and the possessive determiners explain the subject or someone/something else which own something.

Demonstrative reference is reference by means of location, on a scale of proximity (Halliday and Hasan, 1976: 37). The demonstrative reverences found in the editorials of The Jakarta Post May 2011 edition are the, these, those, here, and there are endophoric because the interpretation of the references lies within boundaries of text. Endophora consists of anaphora and cataphora and the reference the, these, those, and here are anaphoric because they are presupposition of something or someone that has gone before. Different from that, the demonstrative here is cataphoric because the reference refers to element that following it. It can be concluded that demonstrative reference refers to the location of a process and they normally do so directly, not via the location of some person or object that is participating in the process.

Comparative reference is indirect reference by means of identity or similarity (Halliday and Hasan, 1976: 37). The comparative reverences found in the editorials of The Jakarta Post May 2011 edition are equal, similar, other, more, less, and as that are deictic numerative comparative references. Equal, similar, and other are general referents where equal is for identity, similar is for similarity, and then other is for difference. More and less are particular demonstrative references. The 
comparative reference equal is anaphoric because it presupposition of something or someone that has gone before. Similar, other, more, less are cataphoric as the presupposition is in following sentence. It is concluded that there are general comparisons in the editorials which express similarities or differences of quality and quantity.

\section{2) Substitution}

Substitution is a relation between linguistic items, such as words or phrases or in the other word, it is a relation on the lexico-grammatical level, the level of grammar and vocabulary, or linguistic form. It is also usually as relation in the wording rather than in the meaning. The criterion is the grammar function of the substitution item. In English, the substitution may function as a noun, as verb, or as a clause. Then, Halliday and Hasan divide the three types of substitution namely nominal, verbal, and clausal (1976: 90).

The elements of nominal substitution are one, ones and same. The substitution one/ ones always function as head of a nominal group, and can substitute only for an item which is itself head of nominal group. Nominal substitution found in the editorials of The Jakarta Post May 2011 edition is one. The nominal substitution one functions as the head of nominal group. It is concluded that nominal substitution one/ ones substitute only for an item which is itself head of a nominal group and it replace a noun phrase in the sentence. Several one in the editorials are anaphoric because the presuppositions are in preceding sentences but another one is exophoric.

The verbal substitution in English is do. This operates as the head of a verbal group, in the place that is occupied by the lexical verb; and it is always in the final position in the group. The substitution do is almost always anaphoric. There is a verbal substitution do which substitutes "quick to jump to the defense of their two fellow politicians" in one of the editorials of The Jakarta Post May 2011 edition. It is concluded that the verbal substitution occurs on verbal group and it substitutes a verb or a verb phrase.

The words used as clausal substitution are so and not. There are three environtments in which clausal substitution take place: report, condition and modality. The clausal substitution found in the editorials of The Jakarta Post May 2011 edition not which substitutes "Much of the anger has not been vented at Yudhoyono". Not is a substitution of conditional clauses. It is concluded that the clausal substitution occurs on the entire clause and the presupposed is a clause. The clausal substitution is anaphoric, because the presuppositions are in preceding sentence.

\section{3) Ellipsis}

The essential characteristic of ellipsis is something that is present in the selection of underlying (systematic) option that omitted in the structure. Halliday and Hasan (1976: 143) say that ellipsis can be regarded as substitution by zero. It is divided into three kinds, namely nominal ellipsis, 
verbal ellipsis, and clausal ellipsis.

Nominal ellipsis means the ellipsis within the nominal group or the common noun that may be omitted and the function of head taken on by one of other elements. Nominal ellipses found in the editorials of The Jakarta Post May 2011 edition are those, some, the other, most, and largest. Those are a specific deictic which function as a head. Some is a non-specific deictic and functions as a head. The other is a post deictic element. Most is an indefinite quantifier and the element of numeral as head. The word largest is a superlative adjectives which functions as epithet as head. All of the ellipsis is cataphoric.

Verbal ellipsis is an elliptical verbal group presupposes one or more words from a previous verbal group. Verbal ellipsis consists of two types that are lexical and operator ellipsis. In the editorials of The Jakarta Post May 2011 edition, the words can and will are lexical ellipsis. They are the types of ellipsis in which the lexical verb is missing from the verbal group. The word accepted is an operator ellipsis because it involves only the omission of operators. All of the verbal ellipses are anaphoric because their presuppositions are in the preceding sentence.

\section{4) Conjunction}

Conjunction is rather different in nature from the other cohesive relation. Conjunctive elements are cohesive not in themselves but indirectly, by virtue of their specific meanings; they are nor primarily devices for reaching out into the preceding (or following) text, but they express certain meaning which presuppose the presence of other components in the discourse. According to Halliday in An Introduction to Functional Grammar (1985: 303), cunjuction is classified into elaboration, extention, and enchancement.

Elaboration means one clause that expands another by elaborating on it (o some portion of it) by restating in other words, specifying in greater detail, commenting, or exemplifying (Halliday, 1985: 196). Elaboration conjunction consists of two kinds that are apposition and clarification. Apposition elaborates other words or phrases or clauses by expository or exemplification. There are some elaborations in the editorials of The Jakarta Post May 2011 edition. The word that is is an opposition that is expository and for example is an exemplification. Clarification elaborates other words or phrases or clauses by reinstated or summarized them. The word rather is a kind of clarification which is corrective and in particular is the same but the word is particularizing.

Extension means one clause expands another by extending beyond it by adding some new element, giving an exception to it, or offering an alternative (Halliday, 1985: 197). Extension involves addition, adversative, and variation. There are some extensions in the editorials of The Jakarta Post May 2011 edition. The conjunction nor is an addition because the word presupposes additional item. But is a conjunction which relates two contrast sentences so the word is adversative. The word except is a variation 
extension conjunction.

Enhancement means one clause expands another by embellishing around it by qualifying it with some circumstantial feature of time, place, cause or condition (Halliday, 1985: 197). Enhancement involves spatiotemporal, manner, causal-conditional, and matter. There are some enhancements in the editorials of The Jakarta Post May 2011 edition. The word soon is a spatio-temporal because it is being used as text creating cohesive devices in term of metaphorical space. Therefore and yet are causal-conditionals because they expand and qualify clauses or sentences with a circumstantial feature of condition.

\section{b. Lexical Cohesion}

Lexical cohesion comes about through the selection of items that are related in some way to those that have gone before (Halliday, 1985: 310). Types of lexical cohesion are repetition, synonymy and collocation. Furthermore, Halliday and Hasan (1976: 288) divide types of lexical cohesion into reiteration (repetition, synonymy or near-synonym, superordinate and general word) and collocation.

\section{1) Reiteration}

Reiteration is categorized into repetition, synonym or near-synonym, superordinate and general word (See Halliday and Hasan, 1976: 288). Repetition is the direct item form lexical cohesion. Some repetitions in the editorials of The Jakarta Post May 2011 edition are hostage and peace. The findings above show that repetition is always repeated by the word in preceding sentence. The words will be repeated in series of sentence. This process creates a relationship of lingual unit to be cohesive. Synonym is used to mean 'sameness of meaning' that is lexical cohesion results from the choice of a lexical item that is in some sense synonymous with a preceding one. In the editorials there are some synonyms or nearsynonyms. The words are graft that refers back to corrupt, firm's which refers back to company, and disappearance which refers back to missing. From the examples, it is concluded that synonym or nearsynonym used to mean meaning sameness in a clause or sentence. Synonym or near-synonym constitutes as lexical cohesion to make the sentence to be cohesive. Superordinate is term for words that refer to the upper class itself. Superordinates in the editorials are the word bribery that refers to upper class which is more general that is criminalization. In other words, criminalization is a superordinate of bribery. There is also the word trucks that refers to upper class which is more general that is vehicles in the next sentence. Furthermore, the word vehicles itself is the member of transportation. It is concluded that superordinate always refer to the upper class which is more general. The general words, which correspond to major classes of lexical items, are very commonly used with cohesive force. They are on the borderline between lexical items and substitutes. There are some general words in the editorials of The Jakarta 
Post May 2011 edition. General word the good things and one thing generalize the following points of a sentence in the data. It is concluded that general words - as found in the editorials of The Jakarta Post May 2011 edition - correspond to major classes of lexical items and they are very commonly used with cohesive force.

\section{2) Collocation}

Collocation has three restrictions that are some are based wholly on the meaning or the item, some are based on range, and some are in the strictest sense (See Halliday and Hasan 1979: 284). The following are the examples of the collocations in the editorials of The Jakarta Post May 2011 edition. The word injuries is a strong collocation with the word violence. Chains of collocation are investors, exporter, and importer. The words are collocational based wholly on their range. It is concluded that collocation - as found in the editorials of The Jakarta Post May 2011 edition - uses the words that have a strong collocational bond and make one sentence cohesive to another.

\section{Coherence in the Editorials of The Jakarta Post}

In general, coherence is the grammatical and semantic interconnectedness between sentences that form a text. Sinclair, Hoey, and Fox (1993: 19) say, "A text can be said to be coherent when each successive sentence can be assigned wholly and without difficulty to one of the relationships..." According to Van Dijk (1997: 9) coherence is how the meaning of sentences in a discourse hung together. Besides that, he distinguished coherence in micro and in macro level analysis. In micro analysis, coherence occurs from the structure of discourse. While in macro analysis, the term coherence develops into topics or themes of discourse. However, Mulyana (2005: 36) says that cohesion and coherence are almost similar because some signs of cohesion aspect are also the signs of coherence aspect. He explains that there are ambiguities between both of the aspects but it is still possible to distinguish them.

D'Angelo (in HG Taringan, 1987: 105 in Mulyana, 2005: 31) asserts that there are some techniques to achieve coherence in a paragraph, they are; repetition of key words of phrases, transitions, pronoun reference. The details of the three types of coherence have explained in the descriptions of grammatical and lexical cohesion devises. In coherence aspect, the three types are accepted as semantic items interconnected with the texts that have been the context of the coherence sign. Here are some examples of application from repetition of key words of phrases, transitions, pronoun reference in text.

\section{a. Repetition}

Repetition in coherence structurally has explained in lexical cohesion. There are some repetitions in the editorials of The Jakarta Post May 2011 
edition (See Keraf, 1984: 76-77).

We highly praise the hostage release - no matter the method and how the shipmen were released - as it had succeeded in bringing all of the 20 men back home safely. And despite the delayed rescue operation by Indonesian Military troops, which was taken only after it was assured that all hostages were safe, the whole hostage release process deserves a two thumbs-up as it broke the record in saving men held hostage at sea in less than 150 days.

Repetition "hostage" in the example tries to create wholeness of the discourse. The word hostage in the topic sentence shows that the discourse is talking about hostage. The following sentence uses the key word to linkage the message that the discourse talking about.

\section{b. Transition}

Transition consists of conjunction as explained in the grammatical cohesion. There are some transitions in the editorials of The Jakarta Post May 2011 edition (See Oshima and Hogue, 1997:108).

Education has remained a non-priority sector, regardless of its huge budget, therefore it comes as no surprise that the state has failed to provide decent rewards for its teachers.

The transition signal therefore builds wholeness or coherency among sentences in a text. It is concluded that transitions are considered as special vocabulary words that spread out of the paragraph or text. Transition makes the movement between sentences in paragraph smooth.

\section{c. Pronoun Reference}

Pronoun in coherence is the same with the explanation of it in reference as the part of grammatical cohesion. There are some pronouns in the editorials of The Jakarta Post May 2011 edition as coherence devices (See Oshima and Hogue, 1997:108).

This newspaper carried a touching reaction of Indomaret employees after being informed of the closure of the shop where they worked in West Jakarta. Employees wept because they knew they would soon join the list of millions of unemployed Indonesians. Hopefully the promise of Indomaret and Alfamart to rotate them to nearby stores would become a reality.

The use of the pronoun they is to hang the meaning of one sentence to the other in the discourse. By the pronoun the reader will understand that every 
sentence in the discourse is a building of an understanding. The description concludes that pronoun is way to achieve coherence of a discourse.

\section{Conclusion}

This paper has examined cohesion and coherence aspects of the editorials of The Jakarta Post May 2011 edition. From the discussion, the cohesion of the Editorials in The Jakarta Post May 2011 Edition consists of grammatical and lexical cohesion. The grammatical cohesion involves reference (personal, demonstrative, comparative), substitution (nominal, verbal, clausal), ellipsis (nominal, verbal, clausal), conjunction (elaborative, extension, enhancement). The lexical cohesion involves reiteration (repetition, synonym or near-synonym, superordinate, general word) and collocation. Coherence of the Editorials in The Jakarta Post May 2011 Edition consists of repetition, transition, and pronoun reference. Repetition is of key words or phrases that are very important to the main idea in a paragraph or text that hung the meaning of a discourse. Transition considered as special vocabulary words that spread out of the paragraph or text. Pronoun reference is to hang the meaning of one sentence to the other in the discourse.

The paper has also created description of the ambiguity between cohesion and coherence aspects and finally concludes that there is a relationship between cohesion with coherence. Coherence is separate from grammatical and lexical cohesion and specifically signifies the semantic meaning of the structure of cohesion. Cohesion and coherence are closely related and support each other. Cohesion refers to linkage of forms, while coherence refers to linkage of meaning. The relation can be seen from the devices of the three items (repetition, transition, and personal reference) are the devices of grammatical and lexical cohesion. The fundamental difference between them is that cohesion is syntactical aspect and coherence is semantically aspect.

The results of the study of cohesion and coherence of the Editorials in The Jakarta Post May 2011 Edition provide practical and theoretical information about discourse analysis. Practically, the research explains about cohesion and coherence devices that are very essential in writing process. Theoretically, research of discourse is still very rare. It is caused by many reasons. The paper at least can be used as a map in understanding the dimension and limitation study of discourse.

\section{References}

Bussmann, Hadumod. 1998. Routledge Dictionary of Language and Linguistics. New York: Routledge.

Halliday, M.A.K and Ruqaiya Hasan. 1976. Cohesion in English. England: Longman.

Halliday, M.A.K 1985. An Introduction to Functional Grammar. Britain: Edward Arnold.

Mahsun, M.S. 2005. Metode Penelitian Bahasa. Jakarta: Rajawali Press. 
Ahmad Dahlan Journal of English Studies (ADJES)

Vol. 3, Issue 2, September 2016

Moleong, Lexy, J. 2002. Metode Penelitian Bahasa. Jakarta: PT Grafindo Persada.

Muhammad. 2011. Penelitian Bahasa: Paradigma Kualitatif. Yogyakarta: Liebe Book Press.

Mulyana. 2005. Kajian Wacana: Teori, Metode, \& Aplikasi Prinsip-prinsip Wacana. Yogyakarta: Tiara Wacana.

Keraf, Gorys. 1984. Komposisi. Jakarta: Nusa Indah.

Van Dijk, A. Teun. 1997. Discourse as Structure and Process. London. SAGE Publications Ltd.

Oshima, Alice and Hogue. 1991. Writing Academic English. San Francisco: Longman. 